\title{
REVIEW
}

\section{How to ventilate obstructive and asthmatic patients}

\author{
Alexandre Demoule ${ }^{1,2^{*}} \mathbb{D}$, Laurent Brochard ${ }^{3,4}$, Martin Dres ${ }^{1,2}$, Leo Heunks ${ }^{5}$, Amal Jubran ${ }^{6}$, Franco Laghi6, \\ Armand Mekontso-Dessap ${ }^{7,8}$, Stefano Nava ${ }^{9}$, Lamia Ouanes-Besbes ${ }^{10,11}$, Oscar Peñuelas ${ }^{12,13}$, Lise Piquilloud ${ }^{14}$, \\ Theodoros Vassilakopoulos ${ }^{15,16}$ and Jordi Mancebo ${ }^{17}$
}

(c) 2020 Springer-Verlag GmbH Germany, part of Springer Nature

\begin{abstract}
Exacerbations are part of the natural history of chronic obstructive pulmonary disease and asthma. Severe exacerbations can cause acute respiratory failure, which may ultimately require mechanical ventilation. This review summarizes practical ventilator strategies for the management of patients with obstructive airway disease. Such strategies include non-invasive mechanical ventilation to prevent intubation, invasive mechanical ventilation, from the time of intubation to weaning, and strategies intended to prevent post-extubation acute respiratory failure. The role of tracheostomy, the long-term prognosis, and potential future adjunctive strategies are also discussed. Finally, the physiological background that underlies these strategies is detailed.
\end{abstract}

Keywords: Mechanical ventilation, Chronic obstructive pulmonary disease, Asthma, Intrisic positive end-expiratory pressure (PEEP), Non-invasive ventilation, Weaning

\section{Introduction}

Respiratory failure from acute exacerbations of chronic obstructive pulmonary disease (COPD) or severe asthma is characterized by acute worsening of respiratory symptoms associated with the development of severe airflow limitation, gas trapping, dynamic hyperinflation and intrinsic positive end-expiratory pressure (PEEPi). In the most severe cases, these exacerbations may cause acute respiratory failure, which may require mechanical ventilation. This review focuses on strategies for ventilation and describes the physiological background that underlies them. Even though the pathogenesis and clinical course of asthma and COPD differ, ventilator support

\footnotetext{
*Correspondence: alexandre.demoule@aphp.fr

1 Service de Pneumologie, Médecine Intensive-Réanimation

(Département "R3S"), Hôpital Pitié-Salpêtrière, AP-HP, Sorbonne Université, 75013 Paris, France

Full author information is available at the end of the article
}

management of the two conditions is similar in various respects.

\section{Acute respiratory failure in COPD and asthma: the magnitude of the problem}

COPD exacerbations are common and have important clinical consequences, including an acute decline in quality of life, temporary or permanent reduction in lung function and exercise capacity, hospitalization, and increased mortality. They also have a major economic impact. According to cohort studies that enrolled unselected critically ill patients receiving mechanical ventilation (invasive or non-invasive) for more than $12 \mathrm{~h} \mathrm{[1]}$, the proportion of patients managed for COPD exacerbation decreased from 10\% in 1998 to 7\% in 2016 (Fig. 1). This trend paralleled an increased rate of non-invasive ventilation (NIV) use as first ventilatory support following intensive care unit (ICU) admission (from 16\% in 1998 to $51 \%$ in 2017). Simultaneously, overall mortality decreased (Fig. 1).

\section{实


Severe asthma exacerbation causing respiratory failure may lead to major mechanical ventilation-associated complications (e.g., barotrauma, cardiovascular collapse, atelectasis, and pneumonia) that can impact on morbidity and mortality. Severe asthma exacerbation accounts for approximately $1 \%$ of mechanically ventilated patients admitted to the ICU [1]. NIV use in these patients increased from 3\% in 1998 to 34\% in 2016 [2].

\section{Respiratory system mechanics and gas exchange}

In terms of respiratory system mechanics, asthma and COPD are characterized by the development of dynamic hyperinflation, defined as increased relaxation volume of the respiratory system at the end of a tidal expiration. In healthy subjects, the end-expiratory alveolar and airway pressures are zero relative to the atmosphere, and pleural pressure is negative. In the presence of dynamic hyperinflation, the alveolar pressure remains positive throughout expiration, leading to the development of auto-positive end-expiratory pressure (auto-PEEP), also termed intrinsic PEEP or PEEPi [3] (Fig. 2).

In COPD, PEEPi is primarily caused by expiratory flow limitation, a complex phenomenon that is due to reduced lung recoil pressure (emphysema) leading to small airway collapse that increases airway resistance (see [4] for an extensive description). It is exacerbated by shortened expiratory time, due to increased respiratory rate, and increased tidal volume, the latter being, in general, a consequence of an augmentation of respiratory drive (and therefore a higher volume to exhale) [5]. The consequences of dynamic hyperinflation depend on whether patients are passively ventilated or triggering their ventilator. In passively ventilated patients, dynamic hyperinflation increases delivered mechanical power [6] with its associated risk of barotrauma and hemodynamic compromise [7]. In patients triggering their ventilator, initiation of inspiratory flow requires inspiratory force to overcome PEEPi [8], which translates into increased inspiratory effort during the triggering phase. Ultimately, this increased effort may fail to trigger the ventilator, leading to ineffective triggering, one of the most frequent dyssynchronies [5]. In terms of gas exchange, patients with COPD have complex patterns of $\mathrm{V} / \mathrm{Q}$ distributions: low $\mathrm{V} / \mathrm{Q}$ regions that remain perfused, high $\mathrm{V} / \mathrm{Q}$ regions, and mixed patterns. COPD patients often exhibit small amounts of shunt (typically less than $10 \%$ of cardiac output) [9].

Severe asthma exacerbation is characterized by a major increase in airway resistance due to bronchospasm, airway inflammation, and mucus. Expiratory flow is dramatically reduced with resultant major dynamic hyperinflation [10]. This leads to an increased risk of

\section{Take-home message}

This review summarizes practical ventilator strategies to manage patients with asthma and chronic obstructive pulmonary disease (COPD). The causes, impact and management of dynamic hyperinflation are discussed, as well as heart-lung interaction. We underline the importance of non-invasive ventilation to prevent intubation. We provide key messages regarding ventilator settings in intubated patients. Future adjunctive strategies are discussed.

barotrauma and hemodynamic compromise. Hypoxemia in asthma is characterized by the presence of low V/Q units; hypoxemia is usually attenuated by compensatory redistribution of blood flow mediated by hypoxic vasoconstriction and changes in cardiac output $[9,11]$. It has been described that in asthma patients, hypercapnia is mainly due to increased dead space ventilation caused by alveolar overdistension $[11,12]$. However, this mechanism has not been proved [9].

\section{Heart-lung interactions in the mechanically ventilated COPD patient}

The pathophysiological changes in the pulmonary system may have adverse effects on cardiac function.

COPD is associated with pulmonary hypertension, increased pulmonary vascular resistance, right ventricle dilatation, and right ventricle hypertrophy. Both left ventricle systolic and left ventricle diastolic functions are often impaired in COPD patients. Among 148 patients admitted to the ICU for severe COPD exacerbation, 31\% had an exacerbation that was definitely associated with left-heart dysfunction [13]. These cardiac alterations are caused by dynamic hyperinflation and the large swings in negative intrathoracic pressure developed by the respiratory muscles to overcome the inspiratory elastic threshold caused by PEEPi and increased airway resistance. Dynamic hyperinflation is more detrimental to left ventricle hemodynamics than large swings in negative intrathoracic pressure [14]. Direct ventricular interaction and significant septal flattening appear to be responsible for reduced left ventricle end-diastolic volume and stroke volume [15]. Dynamic hyperinflation worsens the increase in right ventricular impedance (afterload effect), while large negative intrathoracic pressure swings increase the venous return to the right ventricle (preload effect). Both favor direct ventricular interaction with leftward shift of the septum.

Application of external PEEP up to values approaching PEEPi does not result in hemodynamic impairment in COPD [4]. Higher PEEP levels reduce cardiac index [16]. However, the effects of external PEEP on lung mechanics and hemodynamics depend on many factors, such as airway characteristics, lung volumes, intravascular 

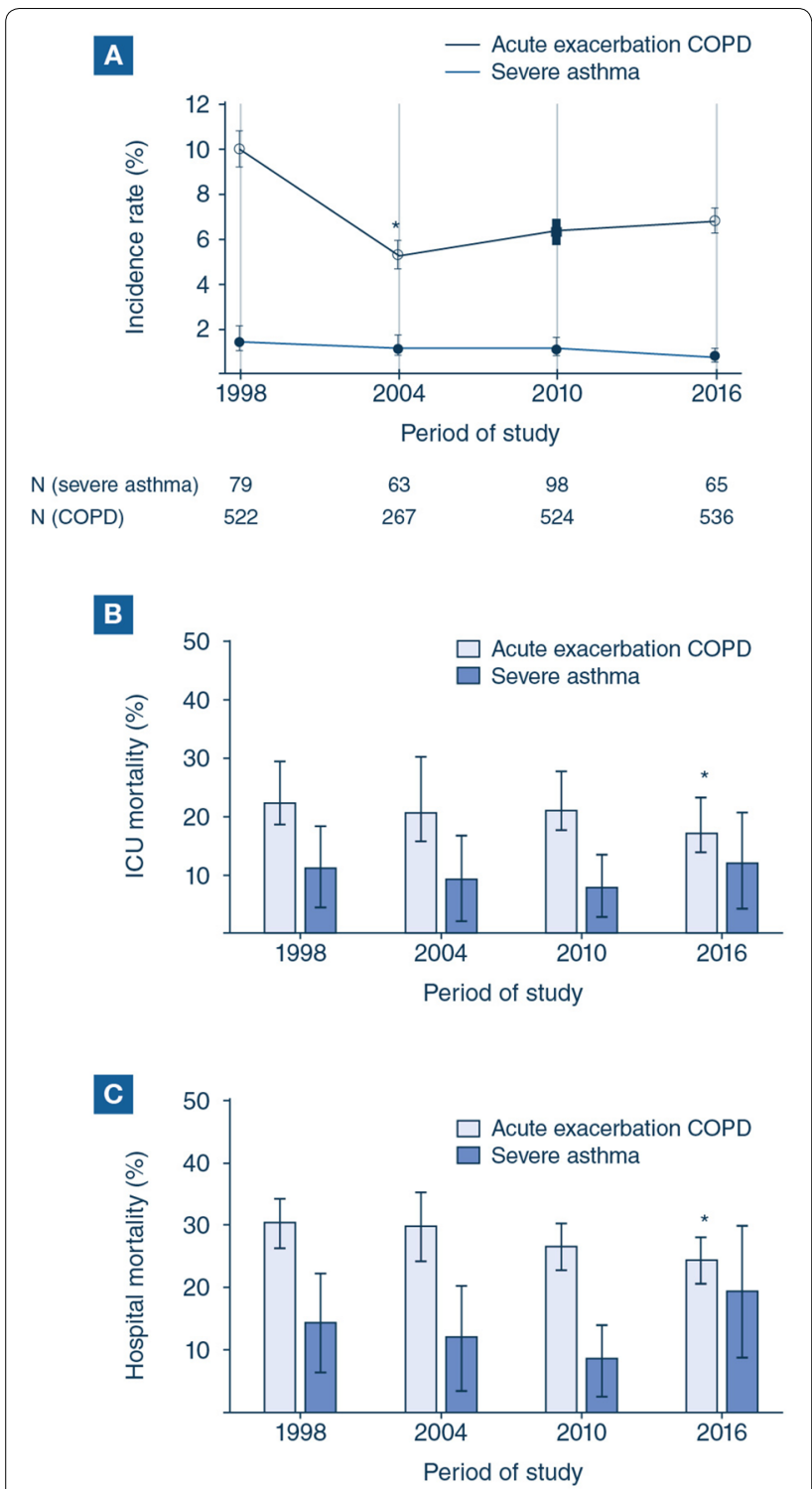

Fig. 1 Rates of acute chronic obstructive pulmonary disease (COPD) exacerbation and severe asthma exacerbation among patients mechanically ventilated for acute respiratory failure (panel $\mathbf{A}$ ) and evolution of ICU mortality (panel B) and hospital mortality (panel C) over time in these two populations. ${ }^{*} p<0.001$ compared to period 1998

volume status, vasomotor tone, etc., making the individual patient's response difficult to predict [17].

Finally, patients with COPD are at increased risk of difficult weaning, and are susceptible to developing weaning-induced pulmonary edema in particular [18]. Diuretics and nitroglycerin are efficient in treating weaning-induced pulmonary edema in selected COPD patients $[19,20]$.
In patients with severe asthma, similar heart-lung interactions are observed. Because of the presence of an extremely severe hyperinflation, they may develop severe hypotension [21].

\section{Non-invasive ventilation in COPD over the decades}

Delivering mechanical ventilation without intubation in patients with $\mathrm{CO}_{2}$ retention was attempted during the 1960s [22], but without becoming widely accepted; intubation with invasive mechanical ventilation remained the rule for patients admitted for respiratory failure.

In the late 1980s, several groups treated patients with chronic or acute-on-chronic hypercapnic respiratory failure with a face mask [23-26]. The success was largely due to combining physiological assessment of the mechanisms of respiratory failure (including respiratory muscle function [26]) with new technologies (pressure support ventilation [27]). In the early 1990s several studies demonstrated the efficacy of positive pressure ventilation usually delivered with pressure support ventilation and PEEP $[28,29]$. It is remarkable that some of the best results were obtained without any PEEP [26], highlighting the importance of pressure delivered during inspiration. Randomized clinical trials showed that the intubation rate was dramatically reduced, resulting in improved outcomes, with fewer complications related to invasive mechanical ventilation and improved hospital survival [30-32] (Fig. 3).

Implementing NIV into practice took more than a decade [33] but NIV became the benchmark for treating acute respiratory failure due to severe COPD exacerbation, bringing about a steady decrease in mortality over time [33]. Concomitantly, the risk of mortality increased in patients transitioned from NIV to invasive mechanical ventilation. However, it is of note that COPD patients who failed NIV and were subsequently intubated were not at higher risk of mortality than those intubated as a first-line respiratory support [30, 33]. Technological improvements continued, stimulated by the need for efficient techniques in the hospital and by the extensive use of home NIV, which required more comfortable and user-friendly equipment [34]. Automated management of leaks progressively became the rule and ICU ventilators eventually became as efficient as dedicated ventilators in compensating for leaks and reducing patient-ventilator dyssynchronies [35, 36].

NIV is sometimes proposed as a ceiling of ventilator assistance care [37-39]. A multicenter French study showed that patients with "do-not-intubate" orders who were managed with NIV had good quality of life 6 months after discharge; caregivers of patients treated with NIV had similar stress and anxiety levels to those of caregivers of patients with no limitation on therapy 
[39]. Because NIV relieves dyspnea [40], the technique has also been used to relieve dyspnea in dying patients receiving palliative care [41], although this approach has not gained widespread use.

In severe asthma exacerbation, retrospective studies have suggested that cautious use of NIV was associated with improved outcome [42]. However, no high-quality randomized controlled trial has highlighted benefits of
NIV in severe asthma exacerbation, and the level of risk may be very high in cases of respiratory failure. As a consequence, guidelines do not recommend NIV in severe asthma exacerbation $[43,44]$.

\section{Management of invasive ventilation}

Invasive ventilation is indicated in patients suffering a respiratory arrest, for instance, or who have failed NIV

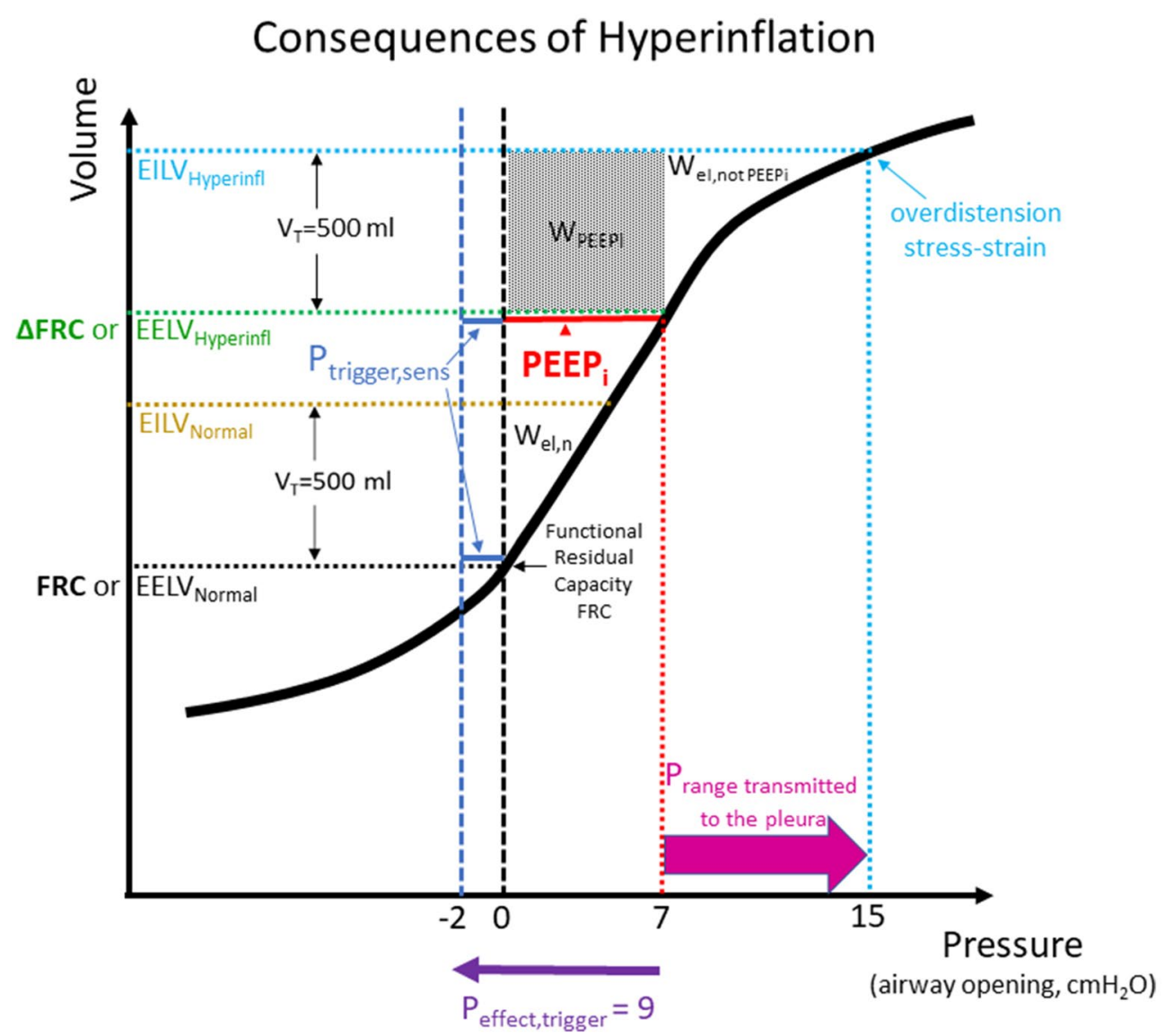

Fig. 2 Pressure-volume (P-V) relationship of the respiratory system when pressure is measured at the airway opening. In normal subjects, the end-expiratory lung volume (EELV $V_{\text {Normal }}$ ) is the relaxation volume of the respiratory system or functional residual capacity (FRC), where no inward or outward recoil pressure exists (the pressure of the respiratory system is $0 \mathrm{cmH}_{2} \mathrm{O}$ relative to the atmosphere). To trigger the ventilator, the patient's inspiratory muscles have to develop an inspiratory effort $\geq$ the trigger threshold set on the ventilator $\left(2 \mathrm{cmH}_{2} \mathrm{O}\right.$ in the example). A tidal breath of $500 \mathrm{ml}$ delivered by the ventilator will increase the volume of the respiratory system to its end-inspiratory lung volume $\left(E_{I L V} V_{\text {Normal }}\right)$. The normal elastic work of breathing $\left(\mathrm{W}_{\mathrm{el}, \mathrm{n}}\right)$ represented by the triangular area is not excessive. In hyperinflated COPD or asthma patients, the end-expiratory lung volume (EELV $V_{\text {Hyperinf }}$ ) is greater than the respiratory system relaxation volume, increasing $\triangle F R C$ ( $\triangle$ denoting the increase in volume from the normal FRC); at this increased volume, an inward recoil pressure exists (the pressure of the respiratory system is $7 \mathrm{cmH}_{2} \mathrm{O}$ relative to the atmosphere). This pressure is called the intrinsic positive end-expiratory pressure (PEEPi). (This pressure is usually measured by the end-expiratory occlusion method with the patient relaxed). To trigger the ventilator, the patient's inspiratory muscles first have to develop an inspiratory effort to overcome the positive inward recoil of the respiratory system present at the end of expiration $\left(7 \mathrm{cmH}_{2} \mathrm{O}, \mathrm{PEEPi}\right)$ and then the trigger threshold set on the ventilator $\left(2 \mathrm{cmH}_{2} \mathrm{O}\right.$ in the example). The pressure required to effectively trigger the ventilator ( $P_{\text {effect,trigger }}=7+2=9 \mathrm{cmH}_{2} \mathrm{O}$ in the example). If they fail to generate this amount $\left(9 \mathrm{cmH}_{2} \mathrm{O}\right)$, an ineffective triggering effort ensues, which does not trigger the ventilator. A similar tidal breath of $500 \mathrm{ml}$

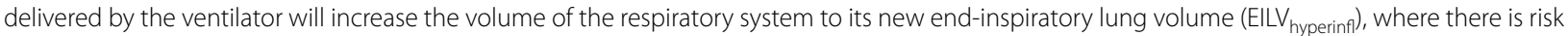
of overdistension (stress and strain of the lung) with its potentially injurious sequalae (this is the plateau pressure if measured by the end-inspiratory occlusion method with the patient relaxed). The elastic work of breathing is mainly attributed to PEEPi (square shaded area, $\mathrm{W}_{\text {PEEPi }}$ ) and is greatly increased leading to increased delivered mechanical power 
for any reason, including persistent clinical signs of increased work of breathing. As previously explained (see above section "Respiratory system mechanics and gas exchange"), acute exacerbations of COPD are characterized by dynamic hyperinflation leading to development of PEEPi. The presence of dynamic hyperinflation and PEEPi should be considered if expiratory flow does not cease at end-expiration (Fig. 4). With controlled mechanical ventilation, total PEEP is measured during endexpiratory occlusion. The reference standard technique for quantifying dynamic hyperinflation is measurement of end-inspiratory lung volume [45]. As this is cumbersome in clinical practice, end-inspiratory plateau pressure (Pplat) during controlled mechanical ventilation is a reasonable, albeit less sensitive, surrogate for monitoring hyperinflation [45]. Pplat is measured with end-inspiratory occlusion for $\pm 3 \mathrm{~s}$. Peak pressure is not a reliable measure for hyperinflation.

It is important to stress that in the early phase of mechanical ventilation, the primary goal in these patients is not to normalize blood gases, but to prevent complications due to hyperinflation while maintaining a $\mathrm{pH}$ of around 7.25-7.30 [46].

Many ventilator modes are used in intubated patients with COPD; however, it is not known whether one is superior to another. A common ventilator mode is volume assist-control ventilation. With volume assistcontrol ventilation, the inspiratory flow waveform can be set in the square pattern to facilitate monitoring of mechanics. To limit hyperinflation, minute ventilation is minimized, and sufficient time is allowed for expiration [45]. As a reasonable starting point, use of a moderate tidal volume, of around $6-8 \mathrm{ml} / \mathrm{Kg}$, and a respiratory rate of $12 / \mathrm{min}$, with constant inspiratory flow delivered at $60-90 \mathrm{l} / \mathrm{min}$, has been proposed [47]. It has been proposed to keep the inspiration-to-expiration ratio low, e.g., 1:4. If, with these ventilator settings, Pplat is not too high (e.g., $<28 \mathrm{cmH}_{2} \mathrm{O}$ ), the respiratory rate can be increased to improve gas exchange. If Pplat is high (e.g. $>28 \mathrm{cmH}_{2} \mathrm{O}$ ), minute ventilation could be reduced by limiting tidal volume and/or respiratory rate in patients with PEEPi. Increasing expiration time at similar minute ventilation (e.g. by increasing inspiratory airflow thus decreasing inspiratory time with constant respiratory rate and tidal volume) has a much smaller effect on hyperinflation [45].

Selecting appropriate PEEP in acute COPD exacerbation may be complex and depends on whether or not the patient triggers her/his ventilator. In general, at the early phase of intubation, patients do not trigger their ventilator. In theory, zero PEEP would be optimal in these COPD patients with "pure" high airway resistance, as PEEP reduces expiratory driving pressure and is therefore expected to increase hyperinflation. However, the physiology appears more complex, with three possible effects of PEEP on hyperinflation [48]: (1) in patients with pure expiratory flow limitation, there is no change in hyperinflation (assessed by Pplat and by changes in end-expiratory lung volume) during progressive increase in PEEP until a threshold is reached; (2) any increase in PEEP increases Pplat and end-expiratory lung volume, and (3) a "paradoxical response" occurs, whereby increases in PEEP decrease Pplat and end-expiratory lung volume. A paradoxical response may be expected in patients with expiratory flow limitation and highly heterogeneous lungs $[7,49]$. At the bedside, the effect of PEEP on hyperinflation is unpredictable [48], and it is therefore advised to measure Pplat while cautiously titrating PEEP. PEEP titration should be immediately stopped if Pplat increases [12].

In passively ventilated patients with expiratory flow limitation, the addition of external PEEP does not change either the degree of hyperinflation or the total PEEP until it approximates $80 \%$ of the original PEEPi. As soon as the patient is able to trigger the ventilator, moderate external PEEP is added to counterbalance PEEPi and hence to reduce the effort needed to trigger the ventilator and improve patient-ventilator interaction [50]. It is of note that patients with COPD are susceptible to ventilatorinduced hyperinflation and dyssynchronies such as ineffective triggering (also called ineffective efforts or wasted efforts, Fig. 5) [50]. Because PEEPi increases the effort required to trigger the ventilator, a weak respiratory effort may fail to trigger it [51]. Ineffective triggering is associated with a less sensitive inspiratory trigger, a higher level of pressure support, a higher tidal volume, and a higher $\mathrm{pH}$ [50]. In patients with a high prevalence of ineffective triggering, markedly reducing pressure support or inspiratory duration to reach a tidal volume of about $6 \mathrm{ml} / \mathrm{Kg}$ predicted body weight was found to eliminate ineffective triggering in two-thirds of patients [52]. When pressure support is used, the pressure support level should not be set too high, to limit tidal volume (to around $6-8 \mathrm{ml} / \mathrm{Kg}$ ) and subsequent dynamic hyperinflation [52]. Shortening insufflation time by decreasing the level of the expiratory trigger (also called cycling-off) may also help to reduce dynamic hyperinflation [52].

In severe asthma exacerbation, invasive mechanical ventilation is associated with an increased risk of complications and significant mortality [53]. Postintubation hypotension is common, due to major lung hyperinflation, hypovolemia and sedation. Therefore, the indication for intubation should be limited to patients in life-threatening conditions (respiratory arrest, bradypnea, altered consciousness, patients totally exhausted and/or with severe and 
worsening hypercapnia or major respiratory distress despite adequate medical treatment). Because of the major increase in expiratory resistance due to airway obstruction related to edema and bronchospasm, pulmonary hyperinflation might be extremely high in asthmatics. The key ventilatory strategy is to minimize hyperinflation, which is best achieved by reducing minute ventilation and lengthening expiratory time (low tidal volume, low respiratory rate [45] and high inspiratory airflow rate with the objective of targeting an inspiratory-to-expiratory time of $1: 4$ to $1: 6)$. A low level of external PEEP $\left(\leq 5 \mathrm{cmH}_{2} \mathrm{O}\right)$ is recommended by some authors, although this strategy is disputed [54]. The degree of hyperinflation must be closely monitored (using end-inspiratory and end-expiratory holds) with the aim of limiting Pplat and obtaining the lowest possible total PEEP [53]. As in COPD, using a volumetric mode with square wave airflow delivery allows easier monitoring. As an effect of major reduction of minute ventilation, $\mathrm{PaCO}_{2}$ might increase dramatically [46]; reduction of $\mathrm{PaCO}_{2}$ is very much a secondary goal.

\section{Weaning from mechanical ventilation}

Readiness to wean needs to be screened on a daily basis according to guidelines (Fig. 3) [55]. In ready-to-wean patients, a spontaneous breathing trial is performed, with either T-tube or pressure support ventilation [56]. In patients who tolerate the spontaneous breathing trial, it is possible to proceed with extubation.

In COPD patients, prophylactic post-extubation NIV and use of high-flow nasal cannula both decrease the occurrence of acute respiratory failure and subsequent reintubation (Fig. 3) $[57,58]$. The addition of NIV sessions to high-flow nasal cannula use seems to be more efficient for preventing reintubation than use of highflow nasal cannula alone [59]. Finally, NIV can also hasten weaning in COPD patients who repeatedly fail spontaneous breathing trials [60].

In a series of 208 patients intubated for hypercapnic respiratory failure, $4.4 \%$ required ventilation via tracheostomy at discharge [61]. The decision to opt for tracheostomy is made on the basis of considerations about, for example, the risks of the procedure versus its anticipated but unproven benefits [62]. In the difficult-to-wean patient, possible tracheostomy should be

\begin{tabular}{|c|c|c|c|c|}
\hline & \multicolumn{2}{|c|}{$\begin{array}{c}\text { Intubation } \\
\downarrow \\
\downarrow\end{array}$} & \multicolumn{2}{|c|}{$\begin{array}{c}\text { SBT } \\
\text { extubation } \\
\downarrow\end{array}$} \\
\hline & $\begin{array}{l}\text { Spontaneous } \\
\text { breathing } \\
\text { Acute respiratory failure }\end{array}$ & $\begin{array}{l}\text { Assist-control mechanical } \\
\text { ventilation }\end{array}$ & $\begin{array}{l}\text { Pressure support or } \\
\text { assist-control ventilation }\end{array}$ & $\begin{array}{l}\text { Spontaneous } \\
\text { breathing } \\
\text { Post-extubation }\end{array}$ \\
\hline 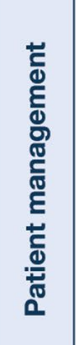 & $\begin{array}{l}\text { NIV to prevent intubation } \\
\text { Can be used as ceiling therapy }\end{array}$ & $\begin{array}{l}\text { - Limit hyperinflation: low tidal } \\
\text { volumes and prolonged expi- } \\
\text { ratory time } \\
\text { - Apply moderate PEEP level } \\
\text { - Do not attempt to normalize } \\
\text { blood gases }\end{array}$ & $\begin{array}{l}\text { - Apply moderate PEEP level } \\
\text { to reduce effort to trigger the } \\
\text { ventilator } \\
\text { - Daily assessment of readiness } \\
\text { to wean } \\
\text { - Tracheostomy requires multi- } \\
\text { disciplinary discussion } \\
\text { - NIV may facilitate weaning in } \\
\text { the case of weaning failure }\end{array}$ & $\begin{array}{l}\text { Consider prophylactic non-in- } \\
\text { vasive ventilation, high-flow } \\
\text { nasal cannula or both to prevent } \\
\text { reintubation }\end{array}$ \\
\hline 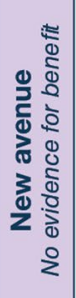 & $\begin{array}{l}\text { - High-flow nasal cannula between } \\
\text { NIV sessions } \\
\text { - Installation of helium/oxygen } \\
\text { mixture to improve } \mathrm{NIV} \text { success } \\
\text { - Extracorporeal } \mathrm{CO}_{2} \text { removal } \\
\text { to avoid intubation } \\
\text { - Diaphragm ultrasound to detect } \\
\text { NIV failure }\end{array}$ & & $\begin{array}{l}\text { - NAVA or PAV to improve patient } \\
\text { ventilator synchrony } \\
\text { - Extracorporeal } \mathrm{CO}_{2} \text { removal } \\
\text { to hasten weaning } \\
\text { - Diaphragm ultrasound to predict } \\
\text { weaning failure }\end{array}$ & \\
\hline 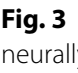 & $\begin{array}{l}\text { apeutic options at the differe } \\
\text { justed ventilator assist; PAV pro }\end{array}$ & $\begin{array}{l}\text { ges of patient management. } N \\
\text { ional assist ventilation }\end{array}$ & on-invasive ventilation, PEEP pos & itive end-expiratory pressu \\
\hline
\end{tabular}


A

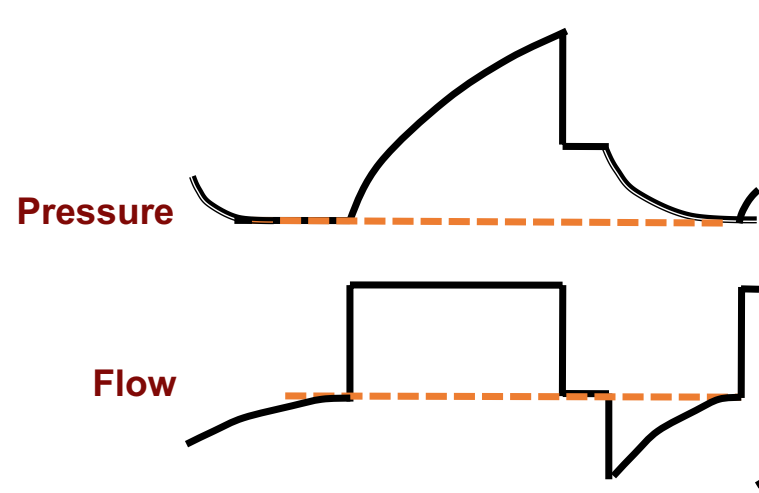

B
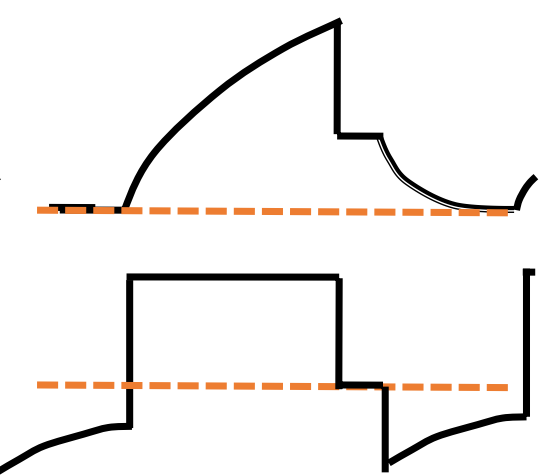

Fig. 4 Schematic representation of pressure and flow recordings in two mechanically ventilated patients. In a healthy subject (panel A) expiratory flow ceases at end-expiration, ruling out dynamic hyperinflation. In a COPD patient (panel B), expiratory flow does not cease at end-expiration, which suggests dynamic hyperinflation and intrinsic positive end-expiratory pressure (PEEPi)

the subject of a multidisciplinary discussion [63]. The patient and his or her family must be informed that tracheostomy does not alter the prognosis of the causal disease. Although tracheostomy can improve comfort [64], it may unduly prolong suffering associated with the underlying illness. In a context of chronic respiratory failure, these ethical considerations must be carefully thought through and discussed with the patient and his or her family before performing a tracheostomy.

\section{Long-term outcome}

In a small series of patients with COPD requiring prolonged mechanical ventilation ( $>21$ days), 2-year survival was $40 \%$ (68\% in patients weaned from the ventilator and $22 \%$ in those not weaned) [65]. In another cohort of patients (59\% with COPD) requiring prolonged ventilation at a weaning center, 1-year survival was $49 \%$ [66].

A prospective longitudinal study investigated the effect of prolonged mechanical ventilation on survival and quality of life in 315 patients with various causes of respiratory failure ( 95 had COPD as primary or secondary cause of respiratory failure) [67, 68]. Among the patients who survived to discharge from the weaning facility, $54 \%$ were detached from the ventilator and $30 \%$ were still attached to the ventilator at the time of discharge from the facility. The 1-year survival was $63 \%$ for ventilator-detached patients and $22 \%$ for the ventilator-attached patients. Survival was not influenced by the underlying cause of respiratory failure, including COPD [68]. By 12 months, the SF36 physical-summary score and mental-summary score returned to pre-illness values, and $85 \%$ of patients indicated their willingness to undergo ventilation again $[68,69]$.

\section{Do particular features emerge in middle-income countries?}

The burden of COPD and asthma is disproportionally high in low-resource countries due to high indoor/outdoor air pollution (smoking, exposure to coal indoors and to dust in the workplace) [70, 71]. The death toll from chronic respiratory diseases is a real challenge to the public health systems in developing countries, since the highest risk of dying from non-communicable disease is observed in low- and middle-income countries [72].

In addition, in most low- and middle-income countries, ICUs are scarce, and resources are limited. The availability of invasive mechanical ventilation, in particular, is limited, and its use is associated with a high risk of mortality, especially from ventilator-associated pneumonia [73-75]. As in high-income countries, NIV should be preferred to invasive ventilation, particularly in cases of COPD exacerbation. A recent meta-analysis summarizing experience of NIV in these countries reported a moderate risk of mortality in adults (16\%), and a mean NIV failure rate of $28.5 \%$ in adults in this population [73]. For COPD exacerbation, the use of NIV as the primary ventilatory mode increased from a rate of $29 \%$ in 2000 to $97 \%$ in 2012 [76]. This change was associated with gradual falls in the rates of NIV failure (learning curve), ventilator-associated pneumonia, and concurrent use of antibiotics [76]. These data suggest that guidelines regarding the preferential use of NIV therapy are not specific to high-income countries and should also be applied to lowand middle-income countries.

\section{New avenues of research}

NIV has well-known drawbacks. Patient tolerance may be poor due to patient discomfort, dyspnea, skin damage, and claustrophobia [40]. Furthermore, caregiver skill 
is important to the success of this technique. High-flow nasal cannula may be an alternative method [77, 78]. In a recent study conducted in 12 hypercapnic COPD patients with mild to moderate exacerbation who had initially required NIV, applying high-flow nasal cannula at $30 \mathrm{l} / \mathrm{min}$ for a short duration reduced inspiratory effort, and resulted in an effect similar to that of NIV delivered at moderate levels of pressure support [78]. In addition, high-flow nasal cannula is a more comfortable technique than NIV $[79,80]$.

Given the fact that approximately $15 \%$ of COPD patients fail NIV, attempts have been made to improve the efficacy of NIV. These attempts include inhalation of helium and oxygen gas mixtures, which requires a complex setting and a specific ventilator. Because of its low density compared with air, helium/oxygen markedly enhanced the ability of NIV to reduce patients' effort and to improve gas exchange [81]. However, despite some improvement of several physiological variables, randomized controlled trials did not show a clinical benefit (i.e., reduction in intubation rate or mortality) $[82,83]$ with the use of helium/oxygen mixture. The relatively low rate of intubation already achieved with NIV alone may explain the lack of benefit with helium/oxygen mixture.

More recently, extracorporeal $\mathrm{CO}_{2}$ removal has been considered as a possible adjunct to NIV to avoid intubation in patients not responding to NIV [84]. Combining $\mathrm{NIV}$ with direct removal of $\mathrm{CO}_{2}$ is postulated to improve
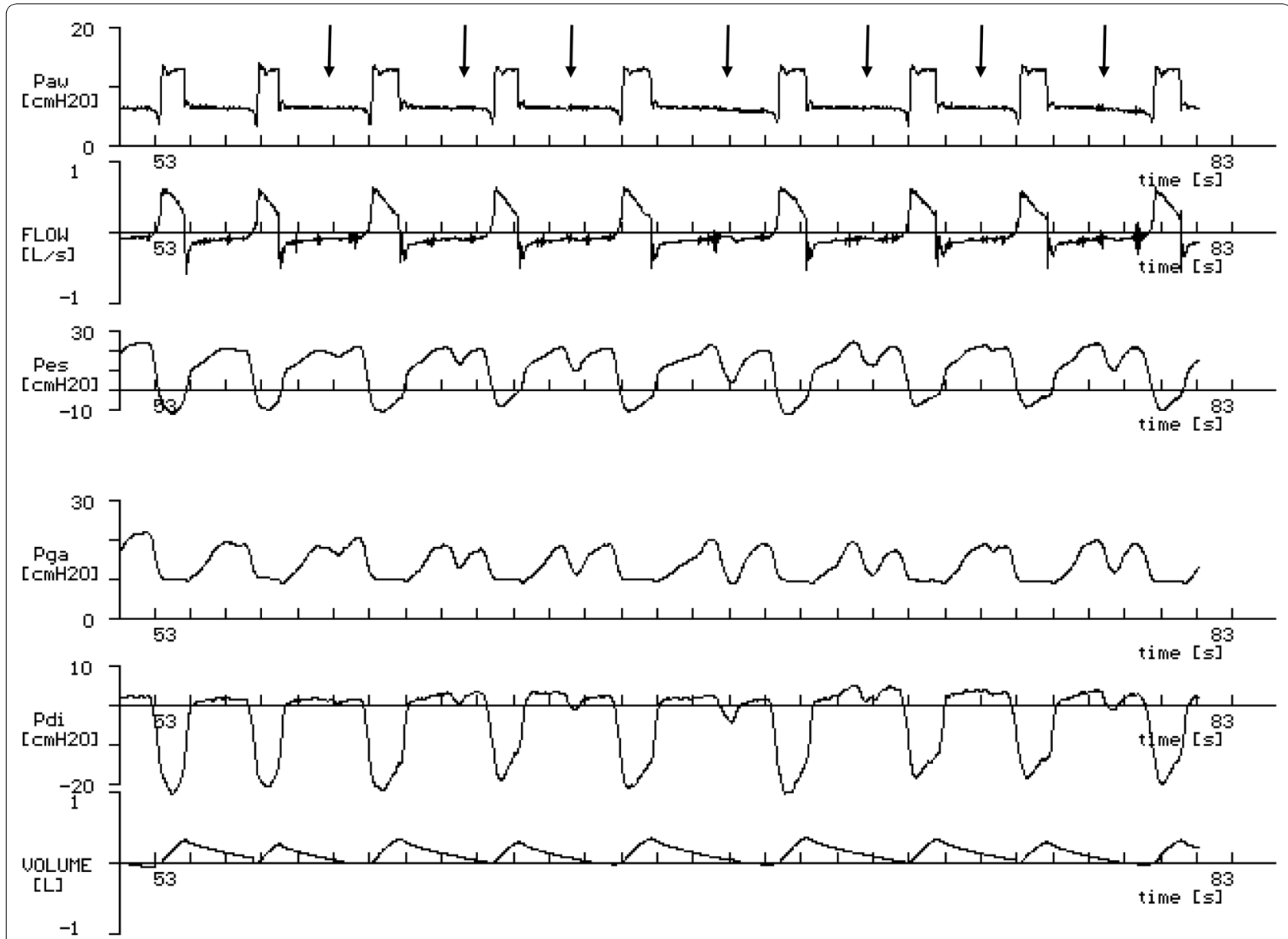

Fig. 5 Tracings (from top to bottom) of airway pressure (Paw), airflow (Flow), esophageal pressure (Pes), gastric pressure (Pga), transdiaphragmatic pressure (Pdi) and tidal volume (VOLUME) in a chronic obstructive pulmonary disease (COPD) patient exhibiting significant respiratory muscle effort during an episode of acute respiratory failure — due to a congestive heart failure during weaning-while mechanically ventilated with positive end-expiratory pressure (PEEP) of $6 \mathrm{cmH}_{2} \mathrm{O}$ and a pressure support level of $8 \mathrm{cmH}_{2} \mathrm{O}$. This patient shows dynamic hyperinflation (average corrected intrinsic PEEPi $8 \mathrm{cmH}_{2} \mathrm{O}$ ), and major recruitment of expiratory muscles (as reflected by the raising Pga during expiration). Of note, the presence of numerous ineffective triggering efforts indicated by the arrows (ventilator respiratory rate is about 18 breaths/min and the patient's respiratory rate is about 28 breaths/min). From Cabello B, Mancebo J (2003) Withdrawal from mechanical ventilation in patients with COPD: the issue of congestive heart failure. In: Vincent J-L (ed) Yearbook of intensive care and emergency medicine. Springer-Verlag, Berlin, Heidelberg, pp 295-301 
alveolar ventilation and reduce the respiratory muscle workload. Extracorporeal $\mathrm{CO}_{2}$ removal can also be used to accelerate weaning from endotracheal intubation as it may prevent ineffective shallow-breathing patterns and reduce inspiratory work by maintaining stable $\mathrm{PaCO}_{2}$ levels during unsupported breathing [85]. Although these devices eliminate carbon dioxide efficiently, experimental evidence of their effectiveness in patients with COPD is limited. Demonstrating benefits in COPD will be challenging because of complications associated with extracorporeal $\mathrm{CO}_{2}$ removal [86].

Another strategy to improve the prognosis of COPD patients is to optimize patient-ventilator interaction. Contrary to what occurs with pressure support ventilation, proportional modes of ventilation assist the patient by delivering a level of assistance that is proportional to his/her inspiratory effort [87]. There are two proportional modes: neurally adjusted ventilatory assist (NAVA) and proportional assist ventilation (PAV). NAVA is a mode that triggers, cycles and regulates inspiratory airflow based on the diaphragmatic electromyography signal. There is no influence of PEEPi during the ventilator assistance, since it starts with the patient's own breathing effort; furthermore, thanks to better patient-ventilator interaction, there should be no effect of leaks during NIV [88-90]. Several studies have shown that NAVA improves patient-ventilator interaction, diaphragm efficiency and patient comfort, as compared with pressure support ventilation [91]. However, no clear clinical advantage of NAVA over PAV has been demonstrated, although NAVA might be beneficial in difficult weaning [91, 92]. With $\mathrm{PAV}$, the inspiratory assist is proportional to the activity of the inspiratory muscles, which is calculated from the measured flow and volumes using the equation of motion of the respiratory system [87]. PAV protects against high tidal volume and subsequent dynamic hyperinflation [93]. The use of PAV is associated with a shorter weaning time compared with pressure support ventilation [94].

A striking feature of patients treated with NIV or invasive ventilation is the high rate of ICU or hospital readmissions [95]. At least $50 \%$ of patients surviving an ICU stay will be readmitted within a year, and this percentage can reach $80 \%$ in some studies. Two factors may explain this high rate. First, patients may continue to need ventilation at home [96], but this practice has not been developed widely. Recent trials of home NIV for patients surviving an ICU admission suggest important potential benefits [34]. Second, many of these patients have untreated or undiagnosed comorbidities, especially sleep-related breathing disorders and cardiac dysfunction $[97,98]$. New approaches are needed to reduce this high readmission rate.
Ultrasound can be used to evaluate respiratory muscle function and help manage mechanically ventilated patients [99], as it can give a gross estimation of diaphragm function [100]. In patients presenting with acute exacerbations of COPD in the emergency room, diaphragm dysfunction was associated with NIV failure [101], but these results have not been prospectively validated. Diaphragm dysfunction is also associated with a higher risk of weaning failure $[102,103]$. Ultrasound can also be used to examine extra-diaphragmatic inspiratory muscle function, focusing on the intercostal parasternal muscle for example [104] (Fig. 6). Increased parasternal intercostal activity is associated with diaphragm dysfunction and weaning failure [104]. Ultrasound can also be applied to image the lungs in COPD, and may be useful in differentiating causes of acute dyspnea in these patients [105]. It can also help in identifying pneumothorax, pleural effusion, consolidation or cardiogenic edema. Whether such ultrasound imaging of the respiratory muscles improves patient outcomes remains to be determined. In addition, training and skills are required to ensure safe and worthwhile implementation.

\section{Summary}

Mechanical ventilation is the cornerstone of the management of COPD and asthma patients presenting with life-threatening respiratory failure. Although NIV prevents the majority of patients with COPD exacerbation from subsequently needing invasive ventilation, future efforts should focus on improving the efficacy of NIV and on evaluation of the high-flow nasal cannula technique. Invasive mechanical ventilation is reserved for patients who fail NIV and are subsequently intubated. The major goal during invasive mechanical ventilation is to limit hyperinflation; this is achieved through reduced minute ventilation, low tidal volumes and prolonged expiratory time. Normalization of blood gas is a secondary therapeutic goal. A low level of external PEEP may be applied to patients triggering their ventilator. Mechanical ventilation of asthma patients follows the same rules except that the use of NIV is not presently recommended despite promising recent data. Weaning should be performed as expeditiously as possible with a daily screening test followed by a trial of spontaneous breathing. In selected patients, prophylactic post-extubation NIV prevents post-extubation acute respiratory failure and subsequent reintubation. High-flow nasal cannula seems as efficient as NIV to prevent reintubation and the combination of NIV and high-flow nasal cannula may be even more efficient. Finally, tracheostomy should be the subject of a multidisciplinary discussion. 


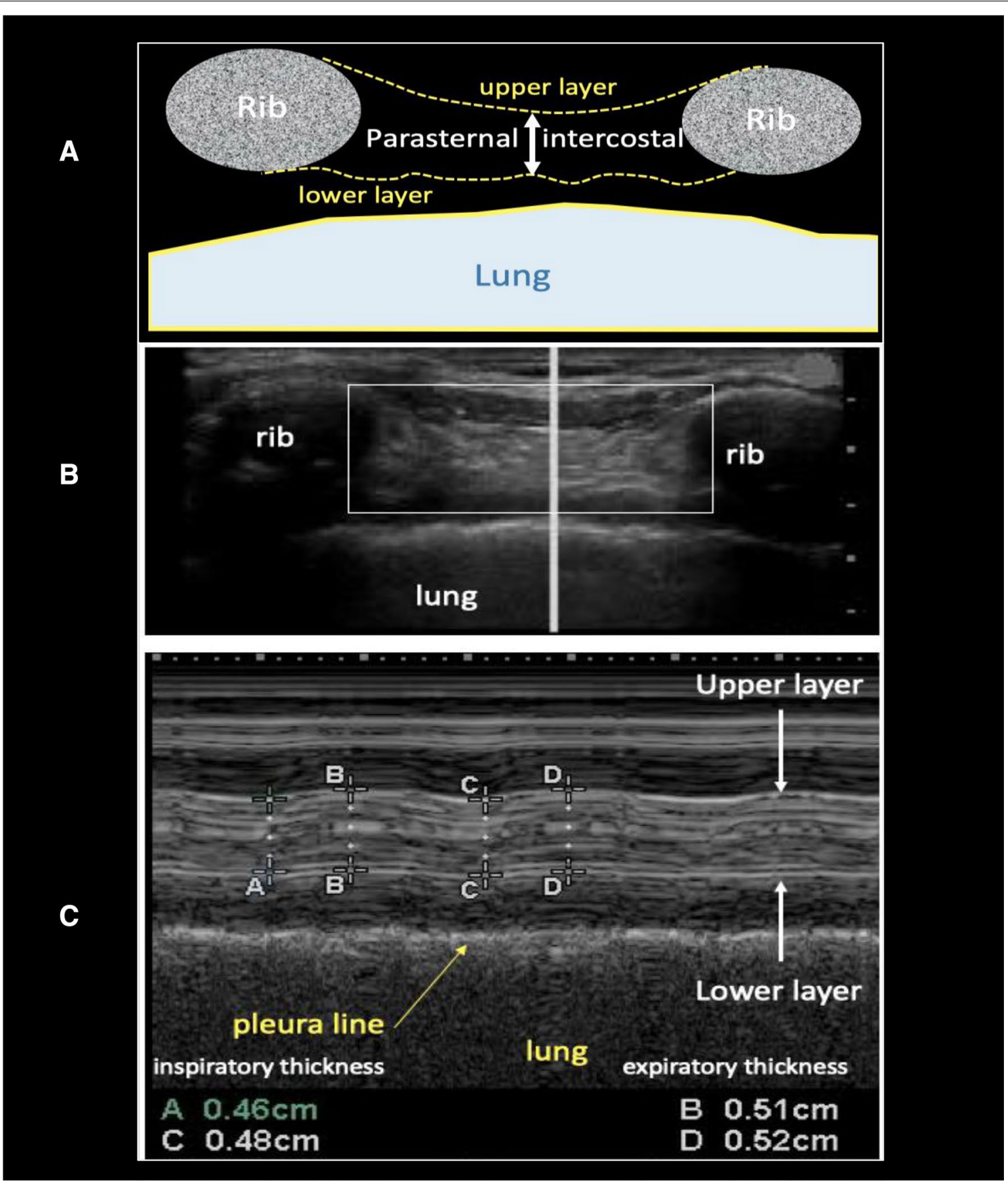

Fig. 6 Schematic representation $(\mathbf{A})$ and ultrasound images of the parasternal intercostal muscle with B mode $(\mathbf{B})$ and time motion mode allowing measurement of inspiratory and expiratory thickness $(\mathbf{C})$

\section{Author details}

'Service de Pneumologie, Médecine Intensive—Réanimation (Département "R3S"), Hôpital Pitié-Salpêtrière, AP-HP, Sorbonne Université, 75013 Paris, France. ${ }^{2}$ INSERM, UMRS1158 Neurophysiologie Respiratoire Expérimentale et Clinique, Sorbonne Université, Paris, France. ${ }^{3}$ Interdepartmental Division of Critical Care Medicine, University of Toronto, Toronto, Canada. ${ }^{4}$ Keenan Centre for Biomedical Research, Li Ka Shing Knowledge Institute, St. Michael's Hospital, Toronto, Canada. ${ }^{5}$ Department of Intensive Care, Amsterdam UMC, Location VUmc, Amsterdam, The Netherlands. ${ }^{6}$ Division of Pulmonary and Critical
Care Medicine, Hines Veterans Affairs Hospital, Loyola University of Chicago Stritch School of Medicine, Hines, IL 60141, USA. ${ }^{7}$ Service de Médecine Intensive Réanimation, AP-HP, Hôpitaux Universitaires Henri Mondor, DHU A-TVB, 94010 Créteil, France. ${ }^{8}$ Faculté de Médecine de Créteil, Université Paris Est Créteil, IMRB GRC CARMAS, 94010 Créteil, France. ${ }^{9}$ Department of Clinical, Integrated, and Experimental Medicine (DIMES), Respiratory and Critical Care, Sant'Orsola Malpighi Hospital, Bologna, Italy. ${ }^{10}$ Intensive Care Unit, Fattouma Bourguiba University Hospital, Rue 1er Juin, 5000 Monastir, Tunisia. ${ }^{11}$ Laboratoire de Recherche (LR12SP15), University of Monastir, Monastir, Tunisia. 
${ }^{12}$ Intensive Care Unit, Hospital Universitario de Getafe, Madrid, Spain. ${ }^{13}$ CIBER de Enfermedades Respiratorias, CIBERES, Madrid, Spain. ${ }^{14}$ Adult Intensive Care and Burn Unit, University Hospital and University of Lausanne, Rue du Bugnon 46, 1011 Lausanne, Switzerland. 15 "Marianthi Simou" Applied Biomedical Research and Training Center, Medical School, Evangelismos Hospital, University of Athens, Athens, Greece. ${ }^{16}$ 3rd Department of Critical Care Medicine, Evgenideio Hospital, Medical School, University of Athens, Athens, Greece. ${ }^{17}$ Intensive Care Department, Hospital Universitari de la Santa Creu i Sant Pau, Barcelona, Spain

\section{Compliance with ethical standards}

\section{Conflicts of interest}

AD reports personal fees from Medtronic, grants, personal fees and nonfinancial support from Philips, personal fees from Baxter, personal fees from Hamilton, personal fees and non-financial support from Fisher \& Paykel, grants from French Ministry of Health, personal fees from Getinge, grants and personal fees from Respinor, grants and non-financial support from Lungpacer, outside the submitted work. LB conducts an investigator-initiated trial on $\mathrm{PAV}+$ (NCT02447692) funded by the Canadian Institute for Health Research and a partnership with Medtronic Covidien; his laboratory also receives grants and non-financial support from Fisher \& Paykel, non-financial support from Air Liquide Medical System, non-financial support from Philips, non-financial support from Sentec, other from General Electric (patent). MD reports personal fees from Lungpacer Med Inc, grants from French Ministry of Heath outside the submitted work. LH reports a research grant paid to institution from Liberate Medical (USA) and speakers fee from Getinge Critical Care. AJ reports grant from the National Institute of Health (RO1-NR016055). FL reports research grants from the National Institutes of Health, VA Research Service, Liberate Medical LLC, and the National Science Foundation, all outside the submitted work. AM-D reports research grants from Fischer Paykel, Baxter, Philips, Ferring and GSK; participation to advisory board for Air Liquide, Baxter, and Amomed, lectures for Getingue and Addmedica. SN report advisory board for Philips and Breas and speaking fee from Resmed Italy outside the submitted work. OP reports no conflict of interest. LO-B reports no conflict of interest. $L P$ reports lecture fees from Hamilton Medical and Getinge and personal fees from Löwenstein, all outside the submitted work. TV reports no conflict of interest. JM reports personal fees from Faron, personal fees from Medtronic, personal fees from Janssen, grants from Covidien (Medtronic) and CIHR, and reimboursement of travel and hotel expenses to attend a meeting from IMT Medical, all outside the submitted work.

\section{Publisher's Note}

Springer Nature remains neutral with regard to jurisdictional claims in published maps and institutional affiliations.

\section{Received: 12 September 2020 Accepted: 12 October 2020}

Published online: 9 November 2020

\section{References}

1. Peñuelas O, Muriel A, Abraira V et al (2020) Inter-country variability over time in the mortality of mechanically ventilated patients. Intensive Care Med 46:444-453. https://doi.org/10.1007/s00134-019-05867-9

2. Pendergraft TB, Stanford RH, Beasley R et al (2004) Rates and characteristics of intensive care unit admissions and intubations among asthmarelated hospitalizations. Ann Allergy Asthma Immunol 93:29-35. https ://doi.org/10.1016/S1081-1206(10)61444-5

3. Vassilakopoulos T, Toumpanakis D, Mancebo J (2020) What's new about pulmonary hyperinflation in mechanically ventilated critical patients. Intensive Care Med. https://doi.org/10.1007/s00134-020-06105-3

4. Junhasavasdikul D, Telias I, Grieco DL et al (2018) Expiratory flow limitation during mechanical ventilation. Chest 154:948-962. https://doi. org/10.1016/j.chest.2018.01.046

5. Vassilakopoulos T (2008) Understanding wasted/ineffective efforts in mechanically ventilated COPD patients using the Campbell diagram. Intensive Care Med 34:1336-1339. https://doi.org/10.1007/s0013 4-008-1095-7
6. Marini JJ, Jaber S (2016) Dynamic predictors of VILI risk: beyond the driving pressure. Intensive Care Med 42:1597-1600. https://doi. org/10.1007/s00134-016-4534-x

7. Marini JJ (2011) Dynamic hyperinflation and auto-positive end-expiratory pressure: lessons learned over 30 years. Am J Respir Crit Care Med 184:756-762. https://doi.org/10.1164/rccm.201102-0226PP

8. Smith TC, Marini JJ (1988) Impact of PEEP on lung mechanics and work of breathing in severe airflow obstruction. J Appl Physiol 65:1488-1499. https://doi.org/10.1152/jappl.1988.65.4.1488

9. Rodriguez-Roisin R, Ferrer A (2013) Effect of mechanical ventilation on gas exchange. In: Tobin MJ (ed) Principles and practice of mechanical ventilation, 3rd edn. The McGraw-Hill Companies, New York, pp 851-867

10. Oddo M, Feihl F, Schaller M-D, Perret C (2006) Management of mechanical ventilation in acute severe asthma: practical aspects. Intensive Care Med 32:501-510. https://doi.org/10.1007/s00134-005-0045-x

11. Young $\mathrm{IH}$, Bye PTP (2011) Gas exchange in disease: asthma, chronic obstructive pulmonary disease, cystic fibrosis, and interstitial lung disease. Compr Physiol 1:663-697. https://doi.org/10.1002/cphy.c0900 12

12. Leatherman JW (2013) Mechanical ventilation for severe asthma. In: Tobin MJ (ed) Principles and practice of mechanical ventilation, 3rd edn. MCGraw Hill, New York, pp 727-739

13. Abroug F, Ouanes-Besbes L, Nciri N et al (2006) Association of leftheart dysfunction with severe exacerbation of chronic obstructive pulmonary disease. Am J Respir Crit Care Med 174:990-996. https://doi. org/10.1164/rccm.200603-3800C

14. Cheyne WS, Williams AM, Harper MI, Eves ND (2016) Heart-lung interaction in a model of COPD: importance of lung volume and direct ventricular interaction. Am J Physiol Heart Circ Physiol 311:H1367-H1374. https://doi.org/10.1152/ajpheart.00458.2016

15. Cheyne WS, Gelinas JC, Eves ND (2018) Hemodynamic effects of incremental lung hyperinflation. Am J Physiol Heart Circ Physiol 315:H474H481. https://doi.org/10.1152/ajpheart.00229.2018

16. Dambrosio M, Cinnella G, Brienza N et al (1996) Effects of positive end-expiratory pressure on right ventricular function in COPD patients during acute ventilatory failure. Intensive Care Med 22:923-932. https:// doi.org/10.1007/BF02044117

17. Georgopoulos D, Giannouli E, Patakas D (1993) Effects of extrinsic positive end-expiratory pressure on mechanically ventilated patients with chronic obstructive pulmonary disease and dynamic hyperinflation. Intensive Care Med 19:197-203. https://doi.org/10.1007/BF01694770

18. Liu J, Shen F, Teboul J-L et al (2016) Cardiac dysfunction induced by weaning from mechanical ventilation: incidence, risk factors, and effects of fluid removal. Crit Care 20:369. https://doi.org/10.1186/s1305 4-016-1533-9

19. Lemaire F, Teboul JL, Cinotti L et al (1988) Acute left ventricular dysfunction during unsuccessful weaning from mechanical ventilation. Anesthesiology 69:171-179. https://doi.org/10.1097/00000542-19880 8000-00004

20. Routsi C, Stanopoulos I, Zakynthinos E et al (2010) Nitroglycerin can facilitate weaning of difficult-to-wean chronic obstructive pulmonary disease patients: a prospective interventional non-randomized study. Crit Care 14:R204. https://doi.org/10.1186/cc9326

21. Corbridge TC, Hall JB (1995) The assessment and management of adults with status asthmaticus. Am J Respir Crit Care Med 151:1296-1316. https://doi.org/10.1164/ajrccm.151.5.7735578

22. Sadoul P, Aug M, Gray R (1965) Traitement par ventilation instrumentale de 100 cas d'insuffisance respiratoire aiguë sévère ( $\mathrm{PaCO} 2$ égale ou supérieure à $70 \mathrm{mmHg}$ ) chez des pulmonaires chroniques. Bull Physiopathol Respir 1:489-505

23. Meduri GU, Conoscenti CC, Menashe P, Nair S (1989) Noninvasive face mask ventilation in patients with acute respiratory failure. Chest 95:865-870. https://doi.org/10.1378/chest.95.4.865

24. Bach JR, Alba AS, Saporito LR (1993) Intermittent positive pressure ventilation via the mouth as an alternative to tracheostomy for 257 ventilator users. Chest 103:174-182. https://doi.org/10.1378/chest.103.1.174

25. Leger P, Jennequin J, Gaussorgues P, Robert D (1988) Acute respiratory failure in COPD patient treated with non invasive intermittent mechanical ventilation (control mode) with nasal mask. Am Rev Respir Dis 137:A63 
26. Brochard L, Isabey D, Piquet J et al (1990) Reversal of acute exacerbations of chronic obstructive lung disease by inspiratory assistance with a face mask. N Engl J Med 323:1523-1530. https://doi.org/10.1056/ NEJM199011293232204

27. Brochard L, Harf A, Lorino H, Lemaire F (1989) Inspiratory pressure support prevents diaphragmatic fatigue during weaning from mechanical ventilation. Am Rev Respir Dis 139:513-521. https://doi.org/10.1164/ ajrccm/139.2.513

28. Brochard L, Mancebo J, Wysocki M et al (1995) Noninvasive ventilation for acute exacerbations of chronic obstructive pulmonary disease. N Engl J Med 333:817-822. https://doi.org/10.1056/NEJM19950928333 1301

29. Bott J, Carroll MP, Conway JH et al (1993) Randomised controlled trial of nasal ventilation in acute ventilatory failure due to chronic obstructive airways disease. Lancet 341:1555-1557. https://doi.org/10.1016/01406736(93)90696-e

30. Demoule A, Girou E, Richard J-C et al (2006) Benefits and risks of success or failure of noninvasive ventilation. Intensive Care Med 32:1756-1765. https://doi.org/10.1007/s00134-006-0324-1

31. Girou E, Brun-Buisson C, Taillé S et al (2003) Secular trends in nosocomial infections and mortality associated with noninvasive ventilation in patients with exacerbation of COPD and pulmonary edema. JAMA 290:2985-2991. https://doi.org/10.1001/jama.290.22.2985

32. Girou E, Schortgen F, Delclaux C et al (2000) Association of noninvasive ventilation with nosocomial infections and survival in critically ill patients. JAMA 284:2361-2367. https://doi.org/10.1001/ jama.284.18.2361

33. Chandra D, Stamm JA, Taylor B et al (2012) Outcomes of noninvasive ventilation for acute exacerbations of chronic obstructive pulmonary disease in the United States, 1998-2008. Am J Respir Crit Care Med 185:152-159. https://doi.org/10.1164/rccm.201106-1094OC

34. Murphy PB, Rehal S, Arbane G et al (2017) Effect of home noninvasive ventilation with oxygen therapy vs oxygen therapy alone on hospital readmission or death after an acute COPD exacerbation: a randomized clinical trial. JAMA 317:2177-2186. https://doi.org/10.1001/ jama.2017.4451

35. Carteaux G, Lyazidi A, Cordoba-Izquierdo A et al (2012) Patient-ventilator asynchrony during noninvasive ventilation: a bench and clinical study. Chest 142:367-376. https://doi.org/10.1378/chest.11-2279

36. Doorduin J, Sinderby CA, Beck J et al (2014) Automated patient-ventilator interaction analysis during neurally adjusted non-invasive ventilation and pressure support ventilation in chronic obstructive pulmonary disease. Crit Care 18:550. https://doi.org/10.1186/s13054-014-0550-9

37. Nava S, Grassi M, Fanfulla F et al (2011) Non-invasive ventilation in elderly patients with acute hypercapnic respiratory failure: a randomised controlled trial. Age Ageing 40:444-450. https://doi. org/10.1093/ageing/afro03

38. Demoule A, Chevret S, Carlucci A et al (2016) Changing use of noninvasive ventilation in critically ill patients: trends over 15 years in francophone countries. Intensive Care Med 42:82-92. https://doi.org/10.1007/ s00134-015-4087-4

39. Azoulay E, Kouatchet A, Jaber S et al (2013) Noninvasive mechanical ventilation in patients having declined tracheal intubation. Intensive Care Med 39:292-301. https://doi.org/10.1007/s00134-012-2746-2

40. Dangers L, Montlahuc C, Kouatchet A et al (2018) Dyspnoea in patients receiving noninvasive ventilation for acute respiratory failure: prevalence, risk factors and prognostic impact: a prospective observational study. Eur Respir J. https://doi.org/10.1183/13993003.02637-2017

41. Nava S, Ferrer M, Esquinas A et al (2013) Palliative use of non-invasive ventilation in end-of-life patients with solid tumours: a randomised feasibility trial. Lancet Oncol 14:219-227. https://doi.org/10.1016/S1470 $-2045(13) 70009-3$

42. Althoff MD, Holguin F, Yang F et al (2020) Noninvasive ventilation use in critically ill patients with acute asthma exacerbations. Am J Respir Crit Care Med. https://doi.org/10.1164/rccm.201910-20210C

43. Le Conte P, Terzi N, Mortamet G et al (2019) Management of severe asthma exacerbation: guidelines from the Société Française de Médecine d'Urgence, the Société de Réanimation de Langue Française and the French Group for Pediatric Intensive Care and Emergencies. Ann Intensive Care 9:115. https://doi.org/10.1186/s13613-019-0584-x
44. Rochwerg B, Brochard L, Elliott MW et al (2017) Official ERS/ATS clinical practice guidelines: noninvasive ventilation for acute respiratory failure. Eur Respir J. https://doi.org/10.1183/13993003.02426-2016

45. Tuxen DV, Lane S (1987) The effects of ventilatory pattern on hyperinflation, airway pressures, and circulation in mechanical ventilation of patients with severe air-flow obstruction. Am Rev Respir Dis 136:872879. https://doi.org/10.1164/ajrccm/136.4.872

46. Darioli R, Perret C (1984) Mechanical controlled hypoventilation in status asthmaticus. Am Rev Respir Dis 129:385-387. https://doi. org/10.1164/arrd.1984.129.3.385

47. Mancebo J (2013) Assist-control ventilation. In:Tobin MJ (ed) Principles and practice of mechanical ventilation, 3rd edn. The McGraw-Hill Companies, New York, pp 159-174

48. Caramez MP, Borges JB, Tucci MR et al (2005) Paradoxical responses to positive end-expiratory pressure in patients with airway obstruction during controlled ventilation. Crit Care Med 33:1519-1528. https://doi. org/10.1097/01.ccm.0000168044.98844.30

49. Leatherman JW, McArthur C, Shapiro RS (2004) Effect of prolongation of expiratory time on dynamic hyperinflation in mechanically ventilated patients with severe asthma. Crit Care Med 32:1542-1545. https://doi. org/10.1097/01.ccm.0000130993.43076.20

50. Laghi $F$ (2013) Mechanical ventilation in chronic obstructive pulmonary disease. In: Tobin MJ (ed) Principles and practice of mechanical ventilation, 3rd edn. MCGraw Hill, New York, pp 741-759

51. Parthasarathy S, Jubran A, Tobin MJ (1998) Cycling of inspiratory and expiratory muscle groups with the ventilator in airflow limitation. Am J Respir Crit Care Med 158:1471-1478. https://doi.org/10.1164/ajrcc m.158.5.9802014

52. Thille AW, Cabello B, Galia F et al (2008) Reduction of patient-ventilator asynchrony by reducing tidal volume during pressure-support ventilation. Intensive Care Med 34:1477-1486. https://doi.org/10.1007/s0013 4-008-1121-9

53. Brenner B, Corbridge T, Kazzi A (2009) Intubation and mechanical ventilation of the asthmatic patient in respiratory failure. Proc Am Thorac Soc 6:371-379. https://doi.org/10.1513/pats.P09ST4

54. Leatherman J (2015) Mechanical ventilation for severe asthma. Chest 147:1671-1680. https://doi.org/10.1378/chest.14-1733

55. Boles J-M, Bion J, Connors A et al (2007) Weaning from mechanical ventilation. Eur Respir J 29:1033-1056. https://doi.org/10.1183/09031 936.00010206

56. Esteban A, Frutos F, Tobin MJ et al (1995) A comparison of four methods of weaning patients from mechanical ventilation. Spanish Lung Failure Collaborative Group. N Engl J Med 332:345-350. https://doi. org/10.1056/NEJM199502093320601

57. Ferrer M, Sellarés J, Valencia M et al (2009) Non-invasive ventilation after extubation in hypercapnic patients with chronic respiratory disorders: randomised controlled trial. Lancet 374:1082-1088. https://doi. org/10.1016/S0140-6736(09)61038-2

58. Hernández G, Vaquero C, Colinas L et al (2016) Effect of postextubation high-flow nasal cannula vs noninvasive ventilation on reintubation and postextubation respiratory failure in high-risk patients: a randomized clinical trial. JAMA 316:1565-1574. https://doi.org/10.1001/ jama.2016.14194

59. Thille AW, Muller G, Gacouin A et al (2019) Effect of Postextubation high-flow nasal oxygen with noninvasive ventilation vs high-flow nasal oxygen alone on reintubation among patients at high risk of extubation failure: a randomized clinical trial. JAMA 322:1465-1475. https:// doi.org/10.1001/jama.2019.14901

60. Burns KEA, Meade MO, Premji A, Adhikari NKJ (2013) Noninvasive positive-pressure ventilation as a weaning strategy for intubated adults with respiratory failure. Cochrane Database Syst Rev. https://doi. org/10.1002/14651858.CD004127.pub3

61. Girault C, Bubenheim M, Abroug F et al (2011) Noninvasive ventilation and weaning in patients with chronic hypercapnic respiratory failure: a randomized multicenter trial. Am J Respir Crit Care Med 184:672-679. https://doi.org/10.1164/rccm.201101-00350C

62. Aquino Esperanza J, Pelosi P, Blanch L (2019) What's new in intensive care: tracheostomy-what is known and what remains to be determined. Intensive Care Med 45:1619-1621. https://doi.org/10.1007/s00134-01905758-z 
63. Trouillet JL, Collange O, Belafia F et al (2018) Tracheostomy in the intensive care unit: guidelines from a French expert panel. Ann Intensive Care 8:37. https://doi.org/10.1186/s13613-018-0381-y

64. Blot F, Similowski T, Trouillet J-L et al (2008) Early tracheostomy versus prolonged endotracheal intubation in unselected severely ill ICU patients. Intensive Care Med 34:1779-1787. https://doi.org/10.1007/ s00134-008-1195-4

65. Nava S, Rubini F, Zanotti E et al (1994) Survival and prediction of successful ventilator weaning in COPD patients requiring mechanical ventilation for more than 21 days. Eur Respir J 7:1645-1652. https://doi. org/10.1183/09031936.94.07091645

66. Schönhofer B, Euteneuer S, Nava S et al (2002) Survival of mechanically ventilated patients admitted to a specialised weaning centre. Intensive Care Med 28:908-916. https://doi.org/10.1007/s00134-002-1287-5

67. Jubran A, Grant BJB, Duffner LA et al (2013) Effect of pressure support vs unassisted breathing through a tracheostomy collar on weaning duration in patients requiring prolonged mechanical ventilation: a randomized trial. JAMA 309:671-677. https://doi.org/10.1001/jama.2013.159

68. Jubran A, Grant BJB, Duffner LA et al (2019) Long-term outcome after prolonged mechanical ventilation. A long-term acute-care hospital study. Am J Respir Crit Care Med 199:1508-1516. https://doi. org/10.1164/rccm.201806-11310C

69. Nava S, Pisani L (2019) Patient-clinician alliance during prolonged mechanical ventilation. "Never give up on a dream." Am J Respir Crit Care Med 199:1453-1454. https://doi.org/10.1164/rccm.201901-0032E D

70. Brakema EA, Tabyshova A, van der Kleij RMJJ et al (2019) The socioeconomic burden of chronic lung disease in low-resource settings across the globe - an observational FRESH AIR study. Respir Res 20:291. https ://doi.org/10.1186/s12931-019-1255-z

71. Menezes AMB, Perez-Padilla R, Hallal PC et al (2008) Worldwide burden of COPD in high- and low-income countries. Part II. Burden of chronic obstructive lung disease in Latin America: the PLATINO study. Int J Tuberc Lung Dis 12:709-712

72. NCD Countdown 2030 collaborators (2018) NCD countdown 2030: worldwide trends in non-communicable disease mortality and progress towards Sustainable Development Goal target 3.4. Lancet 392:1072-1088. https://doi.org/10.1016/S0140-6736(18)31992-5

73. Mandelzweig K, Leligdowicz A, Murthy S et al (2018) Non-invasive ventilation in children and adults in low- and low-middle income countries: a systematic review and meta-analysis. J Crit Care 47:310-319. https:// doi.org/10.1016/j.jcrc.2018.01.007

74. Rosenthal VD, Bijie H, Maki DG et al (2012) International Nosocomial Infection Control Consortium (INICC) report, data summary of 36 countries, for 2004-2009. Am J Infect Control 40:396-407. https://doi. org/10.1016/j.ajic.2011.05.020

75. Markwart R, Saito H, Harder T et al (2020) Epidemiology and burden of sepsis acquired in hospitals and intensive care units: a systematic review and meta-analysis. Intensive Care Med 46:1536-1551. https:// doi.org/10.1007/s00134-020-06106-2

76. Ouanes I, Ouanes-Besbes L, Ben Abdallah S et al (2015) Trends in use and impact on outcome of empiric antibiotic therapy and non-invasive ventilation in COPD patients with acute exacerbation. Ann Intensive Care 5:30. https://doi.org/10.1186/s13613-015-0072-x

77. Seo KW, Ahn J-J, Jegal Y et al (2018) High-flow nasal cannula oxygen therapy for acute hypoxemic respiratory failure in patients with chronic lung disease in terms of hospital outcomes. Intensive Care Med 44:387-388. https://doi.org/10.1007/s00134-017-5018-3

78. Rittayamai N, Phuangchoei P, Tscheikuna J et al (2019) Effects of highflow nasal cannula and non-invasive ventilation on inspiratory effort in hypercapnic patients with chronic obstructive pulmonary disease: a preliminary study. Ann Intensive Care 9:122. https://doi.org/10.1186/ s13613-019-0597-5

79. Longhini F, Pisani L, Lungu R et al (2019) High-flow oxygen therapy after noninvasive ventilation interruption in patients recovering from hypercapnic acute respiratory failure: a physiological crossover trial. Crit Care Med 47:e506-e511. https://doi.org/10.1097/CCM.0000000000003740

80. Ricard J-D, Roca O, Lemiale V et al (2020) Use of nasal high flow oxygen during acute respiratory failure. Intensive Care Med. https://doi. org/10.1007/s00134-020-06228-7
81. Jaber S, Fodil R, Carlucci A et al (2000) Noninvasive ventilation with helium-oxygen in acute exacerbations of chronic obstructive pulmonary disease. Am J Respir Crit Care Med 161:1191-1200. https://doi. org/10.1164/ajrccm.161.4.9904065

82. Jolliet $\mathrm{P}$, Ouanes-Besbes L, Abroug F et al (2017) A multicenter randomized trial assessing the efficacy of helium/oxygen in severe exacerbations of chronic obstructive pulmonary disease. Am J Respir Crit Care Med 195:871-880. https://doi.org/10.1164/rccm.201601-00830C

83. Maggiore SM, Richard J-CM, Abroug F et al (2010) A multicenter, randomized trial of noninvasive ventilation with helium-oxygen mixture in exacerbations of chronic obstructive lung disease. Crit Care Med 38:145-151. https://doi.org/10.1097/CCM.0b013e3181b78abe

84. Del Sorbo L, Pisani L, Filippini C et al (2015) Extracorporeal Co2 removal in hypercapnic patients at risk of noninvasive ventilation failure: a matched cohort study with historical control. Crit Care Med 43:120127. https://doi.org/10.1097/CCM.0000000000000607

85. Pisani L, Fasano L, Corcione N et al (2015) Effects of extracorporeal CO2 removal on inspiratory effort and respiratory pattern in patients who fail weaning from mechanical ventilation. Am J Respir Crit Care Med 192:1392-1394. https://doi.org/10.1164/rccm.201505-0930LE

86. Sklar MC, Beloncle F, Katsios CM et al (2015) Extracorporeal carbon dioxide removal in patients with chronic obstructive pulmonary disease: a systematic review. Intensive Care Med 41:1752-1762. https://doi. org/10.1007/s00134-015-3921-z

87. Jonkman AH, Rauseo M, Carteaux G et al (2020) Proportional modes of ventilation: technology to assist physiology. Intensive Care Med. https ://doi.org/10.1007/s00134-020-06206-z

88. Sinderby C, Navalesi P, Beck J et al (1999) Neural control of mechanical ventilation in respiratory failure. Nat Med 5:1433-1436. https://doi. org/10.1038/71012

89. Sinderby C, Beck J (2014) Neurally adjusted ventilatory assist: first indications of clinical outcomes. J Crit Care 29:666-667. https://doi. org/10.1016/j.jcrc.2014.03.032

90. Schmidt M, Dres M, Raux M et al (2012) Neurally adjusted ventilatory assist improves patient-ventilator interaction during postextubation prophylactic noninvasive ventilation. Crit Care Med 40:1738-1744. https://doi.org/10.1097/CCM.0b013e3182451f77

91. Demoule A, Clavel M, Rolland-Debord C et al (2016) Neurally adjusted ventilatory assist as an alternative to pressure support ventilation in adults: a French multicentre randomized trial. Intensive Care Med 42:1723-1732. https://doi.org/10.1007/s00134-016-4447-8

92. Liu L, Xu X, Sun Q et al (2020) Neurally adjusted ventilatory assist versus pressure support ventilation in difficult weaning: a randomized trial. Anesthesiology 132:1482-1493. https://doi.org/10.1097/ALN.00000 00000003207

93. Giannouli E, Webster K, Roberts D, Younes M (1999) Response of ventilator-dependent patients to different levels of pressure support and proportional assist. Am J Respir Crit Care Med 159:1716-1725. https://doi.org/10.1164/ajrccm.159.6.9704025

94. Kataoka J, Kuriyama A, Norisue Y, Fujitani S (2018) Proportional modes versus pressure support ventilation: a systematic review and metaanalysis. Ann Intensive Care 8:123. https://doi.org/10.1186/s1361 3-018-0470-y

95. Adler D, Cavalot G, Brochard L (2020) Comorbidities and readmissions in survivors of acute hypercapnic respiratory failure. Semin Respir Crit Care Med. https://doi.org/10.1055/s-0040-1710074

96. Macrea M, Oczkowski S, Rochwerg B et al (2020) Long-term noninvasive ventilation in chronic stable hypercapnic chronic obstructive pulmonary disease. An Official American Thoracic Society Clinical Practice Guideline. Am J Respir Crit Care Med 202:e74-e87. https://doi. org/10.1164/rccm.202006-2382ST

97. Adler D, Dupuis-Lozeron E, Janssens JP et al (2018) Obstructive sleep apnea in patients surviving acute hypercapnic respiratory failure is best predicted by static hyperinflation. PLoS ONE 13:e0205669. https://doi. org/10.1371/journal.pone.0205669

98. Adler D, Pépin J-L, Dupuis-Lozeron E et al (2017) Comorbidities and subgroups of patients surviving severe acute hypercapnic respiratory failure in the intensive care unit. Am J Respir Crit Care Med 196:200207. https://doi.org/10.1164/rccm.201608-16660C

99. Tuinman PR, Jonkman AH, Dres M et al (2020) Respiratory muscle ultrasonography: methodology, basic and advanced principles and clinical 
applications in ICU and ED patients-a narrative review. Intensive Care Med 46:594-605. https://doi.org/10.1007/s00134-019-05892-8

100. Dubé B-P, Dres M, Mayaux J et al (2017) Ultrasound evaluation of diaphragm function in mechanically ventilated patients: comparison to phrenic stimulation and prognostic implications. Thorax 72:811-818. https://doi.org/10.1136/thoraxjnl-2016-209459

101. Marchioni A, Castaniere I, Tonelli R et al (2018) Ultrasound-assessed diaphragmatic impairment is a predictor of outcomes in patients with acute exacerbation of chronic obstructive pulmonary disease undergoing noninvasive ventilation. Crit Care 22:109. https://doi.org/10.1186/ s13054-018-2033-x

102. Dres M, Dubé B-P, Mayaux J et al (2017) Coexistence and impact of limb muscle and diaphragm weakness at time of liberation from mechanical ventilation in medical intensive care unit patients. Am J Respir Crit Care Med 195:57-66. https://doi.org/10.1164/rccm.201602-03670C

103. Dres M, Goligher EC, Dubé B-P et al (2018) Diaphragm function and weaning from mechanical ventilation: an ultrasound and phrenic nerve stimulation clinical study. Ann Intensive Care 8:53. https://doi. org/10.1186/s13613-018-0401-y

104. Dres M, Dubé B-P, Goligher E et al (2020) Usefulness of parasternal intercostal muscle ultrasound during weaning from mechanical ventilation. Anesthesiology. https://doi.org/10.1097/ALN.0000000000003191

105. Mayo PH, Copetti R, Feller-Kopman D et al (2019) Thoracic ultrasonography: a narrative review. Intensive Care Med 45:1200-1211. https://doi. org/10.1007/s00134-019-05725-8 